\title{
Correction to: Leaf productivity and persistence have been improved during soybean (Glycine max) domestication and evolution
}

\author{
Ayaka Togashi ${ }^{1} \cdot$ Shimpei Oikawa ${ }^{1} \mathbb{D}$
}

Published online: 20 February 2021

(c) The Botanical Society of Japan 2021

Correction to: Journal of Plant Research

$$
\text { https://doi.org/10.1007/s10265-021-01263-x }
$$

In the original publication of the article, the order of authors was published incorrectly. The correct order is provided in this version.

The original article has been updated.

Publisher's Note Springer Nature remains neutral with regard to jurisdictional claims in published maps and institutional affiliations.

The original article can be found online at https://doi.org/10.1007/ s10265-021-01263-x.

Shimpei Oikawa

shimpei.oikawa.dx@vc.ibaraki.ac.jp

1 Graduate School of Science and Engineering, Ibaraki

University, Mito 310-0056, Japan 